\title{
An Investigation of the Influences of SWOT Sampling and Errors on Ocean Eddy Observation
}

\author{
Chunyong Ma ${ }^{1,2}$, Xiaoxiao Guo ${ }^{1}$, Haoxin Zhang ${ }^{1}$, Jiankai Di $^{1}$ and Ge Chen ${ }^{1,2, *}$ \\ 1 College of Information Science and Engineering, Ocean University of China, No. 238 Songling Road, \\ Qingdao 266100, China; chunyongma@ouc.edu.cn (C.M.); guoxiaoxiao@stu.ouc.edu.cn (X.G.); \\ zhanghaoxin@stu.ouc.edu.cn (H.Z.); dijiankai@stu.ouc.edu.cn (J.D.) \\ 2 Qingdao National Laboratory for Marine Science and Technology, No. 1 Wenhai Road, \\ Qingdao 266200, China \\ * Correspondence: gechen@ouc.edu.cn; Tel.: +86-532-66781265
}

Received: 12 June 2020; Accepted: 18 August 2020; Published: 19 August 2020

\begin{abstract}
The mission of Surface Water and Ocean Topography (SWOT) is scheduled to be launched in 2022, and global ocean eddies with radius scales of larger than $10 \mathrm{~km}$ are expected to be observed from space. However, there are still open questions about the capability of SWOT to detect ocean eddies. Based on ocean model data and SWOT orbit, this study simulates along-track observation of SWOT. Two eddy datasets are derived from simulated observation data via mapping and eddy identification procedures, one of which includes SWOT errors and the other does not. The third eddy dataset is generated from the original model data. Through comparing these three eddy datasets, it is found that $34 \%(40 \%)$ eddies are lost due to insufficient temporal sampling and errors in the Kuroshio Extension (South China Sea) region, and numerous artifact eddies are generated. To further explain the influence of SWOT errors on smaller-scale eddies, two eddies (a cyclonic eddy and an anticyclonic eddy) with the radius of about $10 \mathrm{~km}$ are repeatedly observed 100 times using the SWOT-simulator. The cyclonic eddy with larger amplitude has been detected 84 times, while the anticyclonic eddy is visible 76 times. Therefore, the influence of the SWOT sampling and errors on ocean eddy observation is revealed by the results of these observing system simulation experiments (OSSEs).
\end{abstract}

Keywords: SWOT; space-time sampling; errors; ocean eddies

\section{Introduction}

Ocean eddies play an important role in transporting heat and salt on a global scale [1,2]. In the past two decades, with the development of satellite altimeter technologies, global mesoscale eddies (with radius scales of larger than $\sim 50 \mathrm{~km}$ ) have been detected and scientists study the kinematic properties, propagation characteristics, intrinsic shape and mass transport of mesoscale eddies from a global view [3-8]. However, it is difficult to observe sub-mesoscale eddies (with radius scales of 10-50 km), which are very important to ocean dynamics and biology research, with current nadir altimeters [9-11]. At present, a 2D interferometric altimeter is designed as the primary payload instrument of Surface Water and Ocean Topography (SWOT) and high-resolution sea surface height (SSH) along a wide swath will be measured in the future [12]. Wang et al. [13] investigated the spatial scale resolved by SWOT (SWOT scale), and their results suggested that the SWOT scale, varying geographically and seasonally, can reach $15 \mathrm{~km}$ in a best-case scenario. Consequently, numerous sub-mesoscale eddies will be detected, which is desired for all oceanographers and mariners.

The capability of the satellite altimeter to detect global eddies depends on its space-time sampling and observation errors. On the basis of sampling schemes of current nadir altimeters, with insufficient space coverage, only between $6 \%$ and $16 \%$ of the total number of eddies can be captured [14]. In the 
near future, SWOT will spatially cover almost all ocean areas except polar regions with $120 \mathrm{~km}$ swath width. However, its average revisit time requires approximately 11 days at low latitudes [15]. Considering this insufficient temporal sampling scheme, SWOT will inevitably miss numerous short-term sub-mesoscale eddies. In addition, the instrument noise of the interferometric altimeter and geophysical errors will influence the detection results of eddies, especially sub-mesoscale eddies. The SWOT error document describes the power spectra of the different error components in detail. In this study, these error components are collectively referred to as "observation errors", including the Ka-Band Radar Interferometer (KaRIN) noise, roll errors, baseline dilation errors, phase errors, and timing errors [12,16]. Gaultier et al. [12] investigated how these observation errors impact the SWOT observation and developed the software named SWOT-Simulator, which could synthesize observations of SSH with errors in the spectral domain. The results reveal that SWOT's capability to observe the structure of ocean processes down to 15-30 km in wavelength [17]. However, the mesoscale eddy detection capabilities of SWOT cannot be revealed directly with these curves of the power spectrum. It is necessary to simulate the eddy detection capabilities of SWOT through performing special observing system simulation experiments (OSSEs) [18-20].

This study performed OSSEs to indicate the influences of SWOT sampling and errors on ocean eddy observations. Totally, three types of eddy datasets are derived. First, eddies directly detected from ocean model data are regarded as the ground truth, which can be used for comparison with other results, and this sort of dataset is named "the ground truth eddy dataset $\left(E D_{t}\right)$ ". The second type of eddy dataset is named "the sampling eddy dataset $\left(E D_{S}\right)$ ", which is derived from mapped SSH on the basis of wide-swath sampling data. In this procedure, the ocean model is linearly interpolated in space into the SWOT grid without any noise, and these sampling data have been mapped by employing an optimal interpolation (OI) method. The third type of the dataset called "observed eddy dataset $\left(E D_{0}\right)^{\prime \prime}$ is closer to the eddy detection results by SWOT. Compared with the second dataset, this dataset includes observation errors, which are derived from the SWOT noise power spectrum [12].

Through the comparison of these three types of eddy detection datasets, the coincidence status of eddies (CSE) among different datasets can be extracted. There are five types of CSE defined in this study, which are named "matched", "split", "merged", "missed", and "artifact", respectively. Here, "matched" means the simultaneous observation of an eddy in three datasets, as shown in Figure 1a. Figure 1b,c exhibit the process of "split" and "merged", respectively. After the procedures of simulated observations and mapping, a large eddy in $E D_{t}$ may be "split" into several small eddies in two other datasets, and sometimes several small eddies may be incorrectly "merged" into a large eddy. In addition, the eddy labelled with "missed" cannot be detected by SWOT, and some "artifact" eddies are generated in $E D_{s}$ and $E D_{o}$. According to the analysis of eddy parameters (radius and amplitude) variation corresponding to each type of CSE, the influence of SWOT sampling and errors on eddy detection will be revealed.

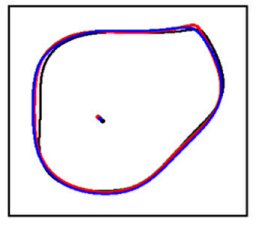

(a) matched

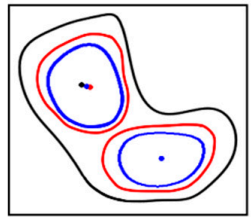

(b) split

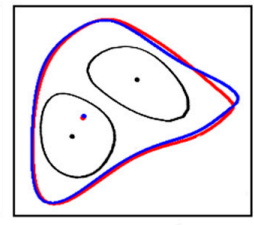

(c) merged

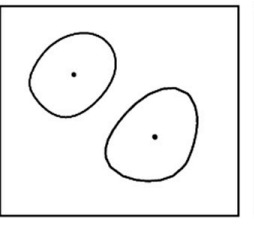

(d) missed

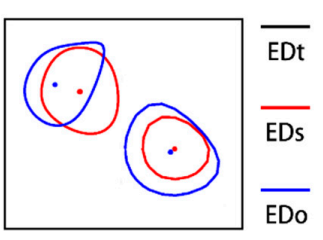

(e) artifact

Figure 1. Illustration of five types of coincidence status of eddies (CSE). Black lines represent the boundaries of eddies in $E D_{t}$. Red and blue lines represent the boundaries of eddies in $E D_{s}$ and $E D_{0}$. (a-e) present examples of "matched", "split", "merged", "missed", and "artifact", respectively. The points denote surface centers of eddies.

In the following, Section 2 provides data and methods. Section 3 illustrates the results of OSSEs in the Kuroshio Extension (KE) region. Section 4 discusses the comparison experiment and the influence of SWOT errors on two smaller-scale eddies. Finally, Section 5 summarizes the key results. 


\section{Data and Methods}

The results of this study are related to four major factors: (1) the SSH model data; (2) the SWOT measurements (sampling and observation errors); (3) the mapping methodology; and (4) the eddy identification algorithm. Here, we concentrate on indicating how the SWOT measurements perform with the assumption that the other three factors are set as specified data or methods. The details of these three factors are described as follows.

\subsection{SSH Model Data}

This study employed Hybrid Coordinate Ocean Model (HYCOM) data, which assimilate the existing satellite altimeter observations, Argo profiles, and other observation data. The SSH data, without tides, are downloaded from HYCOM Center [21]. Several studies investigated the realistic HYCOM model. Among them, a comparison of the variability of SSH shows similar values for the altimeter and HYCOM model [22]. Luecke et al. [23] indicated that the global maps of the mesoscale eddy available potential energy (EAPE) field made by Argo profiles and HYCOM display similar features. Therefore, the eddy amplitudes derived from HYCOM data can be considered realistic and available. This study selects two regions for conducting OSSEs. One is the region encompassing the Kuroshio Extension (KE) in the Northwestern Pacific Ocean $\left(24-44^{\circ} \mathrm{N}\right.$ and $\left.140-180^{\circ} \mathrm{E}\right)$, which is one of the most eddy-energetic regions of the global ocean [24,25]. The other region is the South China Sea (SCS, $5-25^{\circ} \mathrm{N}$ and $105-125^{\circ} \mathrm{E}$ ), where the mean energy of eddies is smaller, and the latitude is lower. By contrasting high and low energy regions at different latitudes, it can be revealed that the effect of eddy amplitude and SWOT sampling density on eddy detection results. To obtain enough eddy data, we employed HYCOM SSH data for the whole year of 2015.

In addition, to understand the influence of SWOT errors on smaller-scale eddies more clearly, another high-resolution numerical dataset has been employed in Section 4, which is the Regional Ocean Modeling System (ROMS) model dataset off the Oregon coast [26]. These SSH data range from $42^{\circ} \mathrm{N}$ $\left(124^{\circ} \mathrm{W}\right)$ to $48^{\circ} \mathrm{N}\left(130^{\circ} \mathrm{W}\right)$ and are available online [27]. More details of SSH model data are shown in Table 1.

Table 1. Summary of the sea surface height (SSH) model data.

\begin{tabular}{|c|c|c|c|}
\hline Coverage & Model/Type & $\begin{array}{l}\text { Spatial Resolution } \\
\text { Lat } \times \text { Lon }\left({ }^{\circ}\right)\end{array}$ & $\begin{array}{c}\text { Temporal } \\
\text { Resolution (Day) }\end{array}$ \\
\hline $\begin{array}{c}\text { KE } \\
\left(24-44^{\circ} \mathrm{N} \text { and } 140-180^{\circ} \mathrm{E}\right)\end{array}$ & \multirow{2}{*}{$\begin{array}{l}\text { HYCOM/ } \\
\text { Gridded }\end{array}$} & \multirow{2}{*}{$1 / 12.5^{\circ} \times 1 / 12.5^{\circ}$} & \multirow{2}{*}{1 day } \\
\hline $\begin{array}{c}\text { SCS } \\
\left(5-25^{\circ} \mathrm{N} \text { and } 105-125^{\circ} \mathrm{E}\right)\end{array}$ & & & \\
\hline $\begin{array}{c}\text { Oregon Coast } \\
\left(42-48^{\circ} \mathrm{N} \text { and } 124-130^{\circ} \mathrm{W}\right)\end{array}$ & $\begin{array}{l}\text { ROMS/ } \\
\text { Gridded }\end{array}$ & $\begin{array}{c}1 / 170^{\circ} \times 1 / 130^{\circ} \\
(\sim 0.6 \mathrm{~km} \times 0.6 \mathrm{~km})\end{array}$ & 1 day \\
\hline
\end{tabular}

\subsection{Mapping Procedure Based on Optimal Interpolation}

As the most popular data mapping algorithm of altimetric satellites, the optimal interpolation method is evolved from the objective analysis [28] and has been utilized in AVISO (Archiving, Verification and Interpretation of data of Satellites Oceanography) [29]. The mapping results $S(X)$ can be estimated as follows:

$$
S(X)=\sum_{i=1}^{N} \sum_{j=1}^{N} A_{i j}^{-1} C_{X i} \Phi_{o b s}^{i}
$$

where $\phi_{o b s}^{i}(i=1,2,3, \ldots, N)$ is the observation value, and $A$ represents the covariance matrix for the observations themselves. $C$ is the covariance matrix between the observations and the field to be estimated. The calculation formulas of these are as follows: 


$$
\begin{gathered}
A_{i j}=\left\langle\Phi_{o b s}^{i} \Phi_{o b s}^{j}\right\rangle=F\left(X_{i}-X_{j}\right) \\
C_{X i}=\left\langle S(X) \Phi_{o b s}^{i}\right\rangle=F\left(X-X_{i}\right)
\end{gathered}
$$

$F$ is the space-time correlation function. In this study, the correlation function utilizes the Gaussian function consistent with the study of Amores et al. [14], as shown in Formula (4):

$$
F(\Delta x, \Delta y, \Delta t)=e^{-\frac{\sqrt{(\Delta x)^{2}+(\Delta y)^{2}}}{R^{2}}} \cdot e^{-\frac{(\Delta t)^{2}}{T^{2}}}
$$

where $(\Delta x, \Delta y, \Delta t)$ is the space-time difference between two points, which are $X_{i}$ and $X_{j}$ in Formula (2), as well as $X$ and $X_{i}$ in Formula (3). The $R$ and $T$ are the correlation distance in the space and time. In this study, the $R$ and $T$ are set as $50 \mathrm{~km}$ and 10 days, respectively, so that the root mean square errors (RMSE) between the model and mapping data can be minimized. The RMSE is $4.9 \mathrm{~cm}(3.4 \mathrm{~cm})$ in the KE (SCS).

\subsection{Eddy Identification}

The sea level anomaly (SLA) data can be derived by removing mean sea surface (MSS) from SSH, and the MSS data (MSS_CNES_CLS_15) are downloaded from AVISO. A three-step eddy identification method similar to Mason et al. [30] is applied in this paper. First, individual SLA fields are spatially high-pass filtered using a Gaussian filter with a zonal/meridional radius of $10^{\circ} / 5^{\circ}$. Second, the local SLA maximum/ minimum is extracted, whose value is greater (smaller) than its 24 neighbors (within a $5 \times 5$ pixel box). Third, SLA contours are computed at $0.1 \mathrm{~cm}$ intervals. A closed SLA contour is searched from the local SLA minimum (maximum) value upward (downward) until 0 to identify a cyclonic (an anticyclonic) eddy based on the following criteria:

(1) Contain no more than one local SLA maximum/minimum;

(2) Contain a pixel count, $I$, satisfying $8 \leq I \leq 3000$;

(3) Pass a shape test with error $\leq 55 \%$, where the error is defined as the ratio between the areal sum of closed SLA contour deviations from its fitted circle and the area of that circle (more details can be found in Mason et al. [30]);

(4) Amplitude $\geq 0.3 \mathrm{~cm}$.

Then, the outermost SLA contour that satisfies all the above conditions is extracted as the effective perimeter of the eddy. It should be noted that the minimum amplitude threshold is $1 \mathrm{~cm}$ in Mason et al. [30], which is on the basis of SLA data from AVISO $\left(0.25^{\circ}\right)$. The spatial resolution of HYCOM SLA data is $0.08^{\circ}$, which is 3.125 times that of AVISO data $\left(0.25^{\circ} / 0.08^{\circ}=3.125\right)$, so the minimum amplitude threshold in this study is linearly scaled to $0.3 \mathrm{~cm}(1 \mathrm{~cm} / 3.125 \approx 0.3 \mathrm{~cm})$. Besides, considering the sampling errors enhanced along the ocean-land boundaries [31], the eddies over the shelf shallower than $100 \mathrm{~m}$ are removed in this study.

\subsection{CSE Determination}

As described in Section 1, five types of CSE have been defined. To determine the CSE type of an eddy $e_{a i}$ in dataset $E D_{a}$, it is a crucial step to find $k$ eddies $\left(e_{b 1}, e_{b 2}, \ldots e_{b k}\right)$ with similar spatiotemporal information in another dataset $E D_{b}$, which is named as "space-time matching". Moreover, the eddy $e_{b j}$ $(j \in[1, k])$ in $E D_{b}$ is supposed to be selected with the following conditions:

$$
\begin{gathered}
\mid \text { Centera }_{i}-\text { Centerb }_{j} \mid \leq R a_{i} \\
\text { Typea }_{i}=\text { Typeb }_{j}
\end{gathered}
$$

where Centera $a_{i}$ and Centerb $b_{j}$ represent the surface center positions of eddy $e_{a i}$ and $e_{b j}$, respectively. The radius of eddy $e_{a i}$ is $R a_{i}$ in Formula (5). Their polarizations (including the cyclone and the anticyclone) labelled with Typea ${ }_{i}$ and Typeb $b_{j}$ should be same, as shown in Equation (6). After the 
procedure of space-time matching, a sub dataset $E D_{b s u b}$ containing $k$ eddies can be derived. Meanwhile, the closest eddy $e_{b c l o s e s t}$ in $E D_{b s u b}$ can be extracted, whose center is closest to that of $e_{a i}$. A vector $\left(k_{a}, k_{b}\right)$ can be used to describe CSE between $E D_{a}$ and $E D_{b}$. As described above, the value of $k_{a}$ is 1 and that of $k_{b}$ is equal to $k$. Furthermore, we introduce a vector $K\left(k_{t}, k_{s}, k_{o}\right)$ to describe CSE among three datasets, where the $k_{t}, k_{s}$ and $k_{o}$ are corresponding to $E D_{t}, E D_{s}$ and $E D_{o}$, respectively. The labels of CSE defined based on $K$ are shown in Table 2. For example, $K(1,2,2)$ represents that there is 1 eddy exists in $E D_{t}$, and 2 space-time matching eddies can be found in $E D_{s}$ and $E D_{o}$. Therefore, these 5 eddies will be labelled with "split".

Table 2. $K\left(k_{t}, k_{s}, k_{o}\right)$ and CSE lookup table.

\begin{tabular}{cccc}
\hline $\boldsymbol{k}_{\boldsymbol{t}}$ & $\boldsymbol{k}_{\boldsymbol{s}}$ & $\boldsymbol{k}_{\boldsymbol{o}}$ & CSE \\
\hline 1 & 1 & 1 & matched \\
\hline 1 & $>1$ & $>1$ & \\
1 & $>1$ & 1 & split \\
1 & 1 & $>1$ & \\
\hline$>\mathbf{1}$ & 1 & 1 & merged \\
\hline 1 & 0 & 0 & \\
1 & $\geq 1$ & 0 & missed \\
1 & 0 & $\geq 1$ & \\
\hline 0 & 1 & 1 & \\
0 & 1 & 0 & artifact \\
0 & 0 & 1 & \\
\hline
\end{tabular}

Every eddy in these three datasets can be uniquely labelled with different CSE through following Algorithm 1:

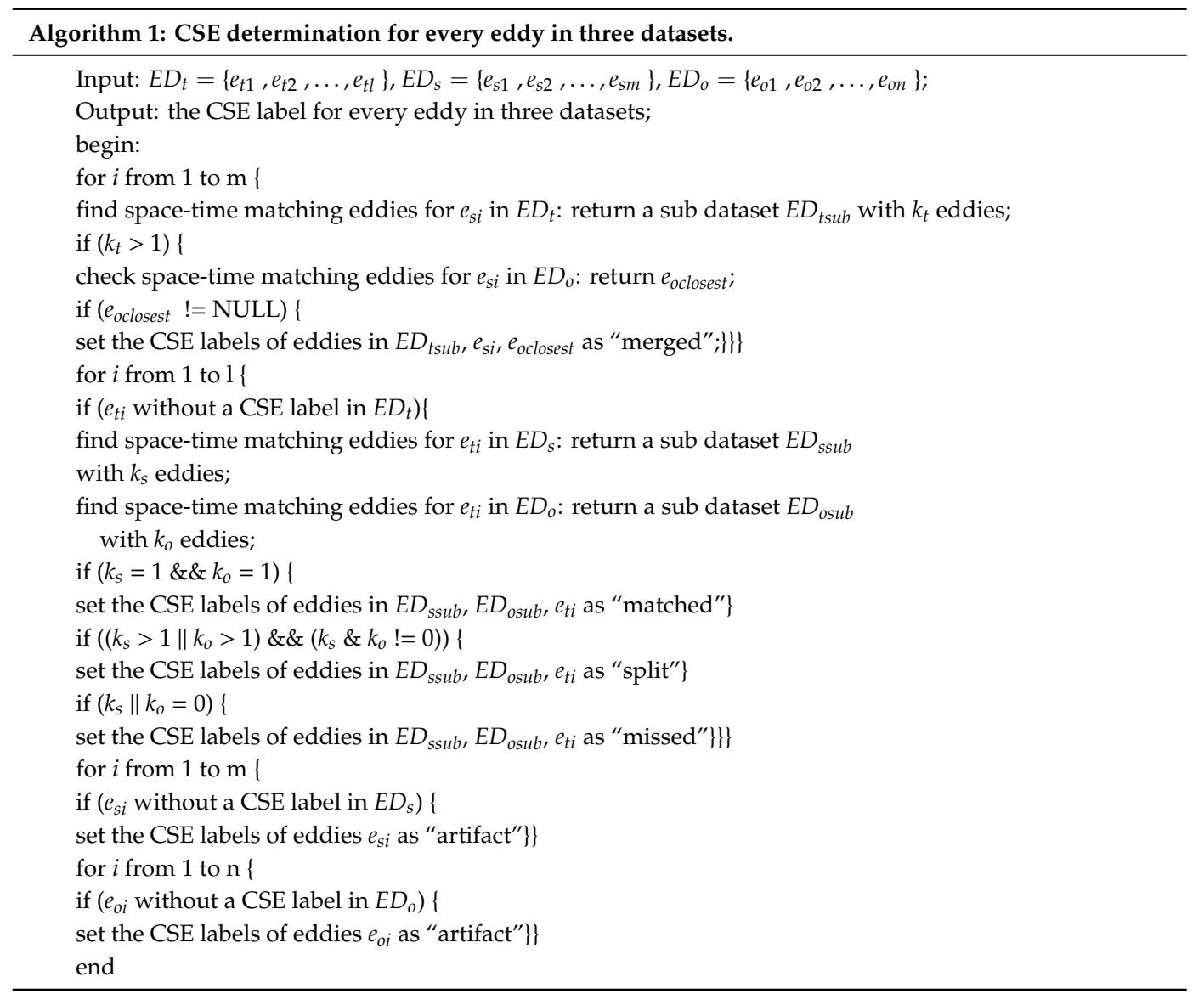




\section{Results of OSSEs in the Kuroshio Extension (KE) Region}

The OSSEs in the KE region have been conducted in combination with the information of SWOT satellite orbit and the noise power spectrum from the SWOT document [15]. As a result, three eddy datasets of the KE region named KE-EDt, KE-EDs, and KE-EDo for one year (2015) are obtained. Based on the spatial resolution $\left(0.08^{\circ}\right)$ of HYCOM, the effective radius defined same as Mason et al. [30] should be larger than $12 \mathrm{~km}$ in KE region. To show the results of eddy identification, the data on 12 January 2015 are selected randomly and plotted in Figure 2.
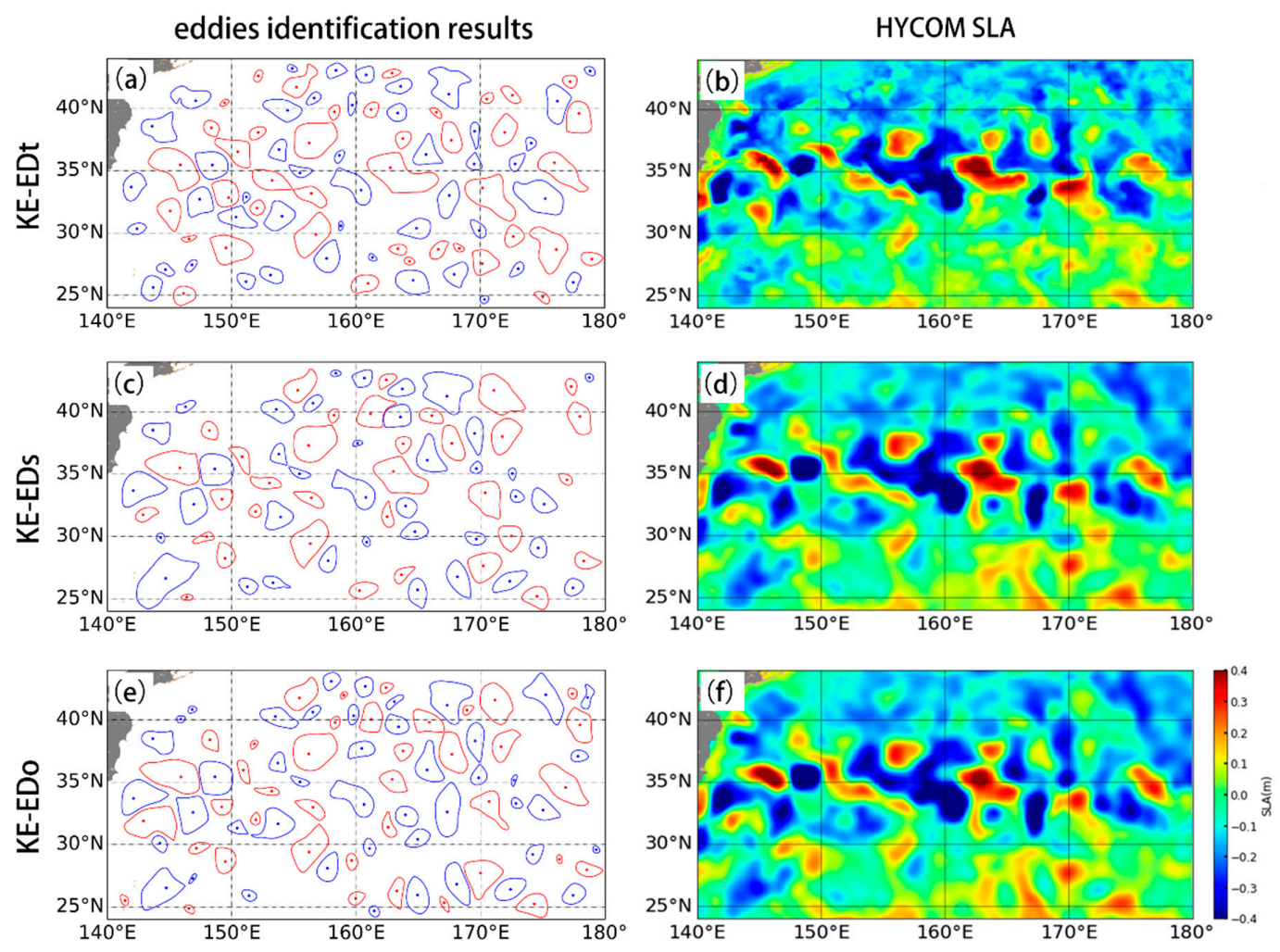

Figure 2. Snapshots of eddies and corresponding SLA data on 12 January 2015. (a,c,e) show the eddy identification results in the KE-EDt, KE-EDs, and KE-EDo dataset, respectively. The blue (red) lines represent the effective perimeter of cyclonic (anticyclonic) eddies, and the blue (red) points represent their surface centers. $(\mathbf{b}, \mathbf{d}, \mathbf{f})$ show SLA data corresponding to $(\mathbf{a}, \mathbf{c}, \mathbf{e})$, respectively.

To generally compare these three datasets of KE-EDt, KE-EDs, and KE-EDo, their geographical distributions of the averaged radius and amplitude are illustrated in Figure 3. Their spatial patterns are similar and basically featured with a strengthen zone near $35^{\circ} \mathrm{N}$, which is consistent with the spatial distributions of eddies with high amplitudes detected by altimeters in Itoh et al. [32]. As an energetic eastward flowing inertial jet, the KE is characterized and surrounded by a complicated ocean circulation structure, which is flanked by anticyclonic and cyclonic recirculation gyres in the south and north, respectively [33]. These strong eddies near the axis of the KE are primarily shed from the KE jet and owing to its perturbations of the jet [34]. 

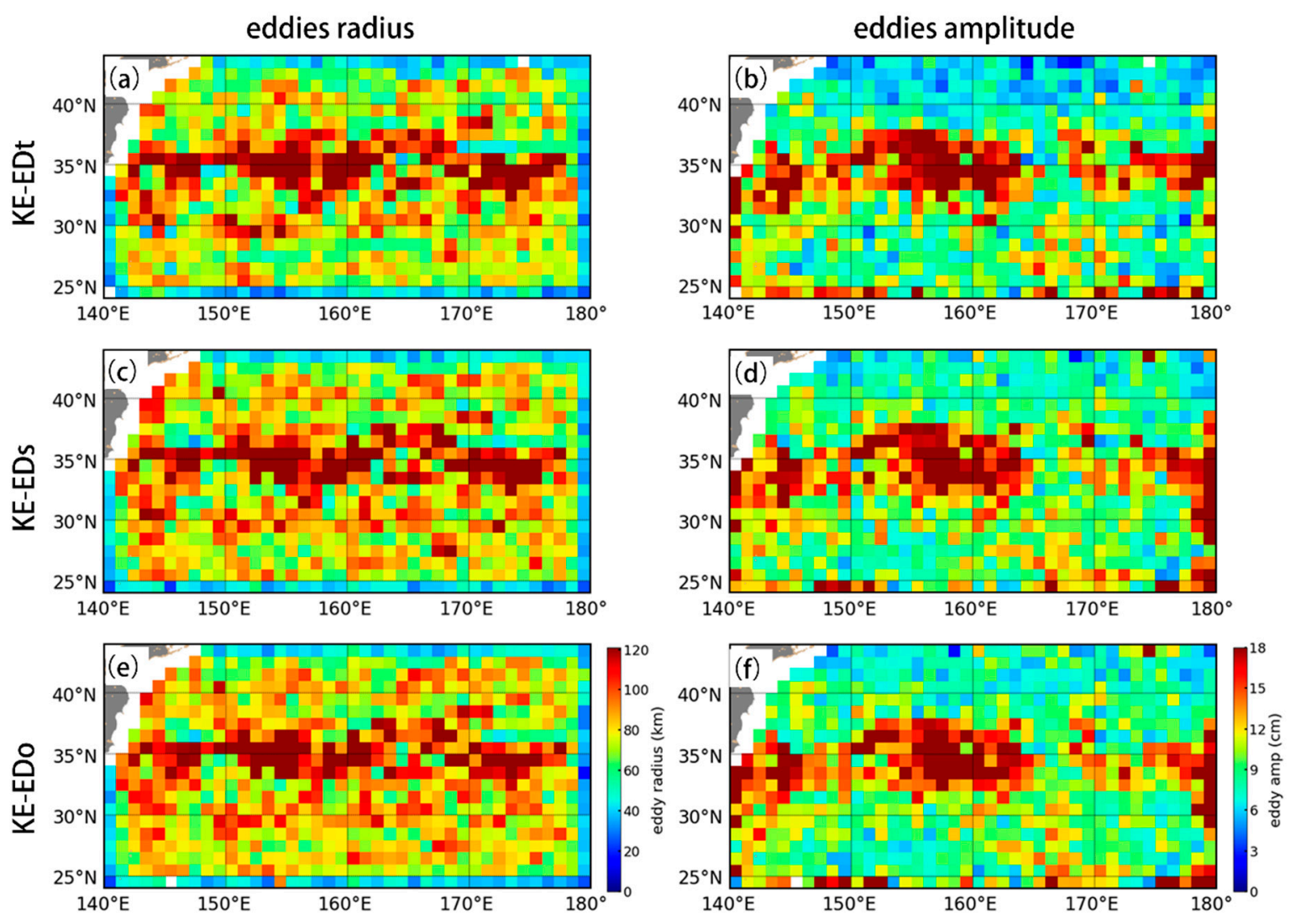

Figure 3. Geographical distribution of the averaged radius and amplitude on a $1^{\circ} \times 1^{\circ}$ grid for $(\mathbf{a}, \mathbf{b})$ KE-EDt, (c,d) KE-EDs, and (e,f) KE-EDo, respectively.

After conducting the algorithm of CSE determination as described in Section 2.4, every eddy in these three datasets has been uniquely labelled with a CSE type. According to Figure 4, eddies of the "matched" type account for the highest proportion, followed by the eddies of "missed" and "artifact" types. Besides, a small number of eddies are labelled with "split" and "merged".

Although eddies are labelled with "matched" in Figure $4 \mathrm{~b}$, the effective perimeters of eddies in the three datasets plotted with three colored lines (black, red, and blue) rarely coincide completely. The differences between the red and the black lines are caused by the sampling and mapping procedures, and the differences between the blue and red lines are due to observation errors. The black lines in Figure $4 \mathrm{c}$ indicate the effective perimeters of "missed" eddies in KE-EDt, among which some eddies are missed considering insufficient temporal sampling, such as eddy1 in Figure 4c. Although the effective radius of eddy 1 has reached $136 \mathrm{~km}$, the sample data during a period (21 days) centered on 12 January 2015 do not have enough information to reconstruct the eddy after the mapping procedure. Obviously, the insufficient temporal sampling will bring about the loss of both eddies with the small radius and some large eddies. Other eddies are missed on account of observation errors, such as the eddy 2 in Figure 4c, whose radius is $30 \mathrm{~km}$, and its amplitude is $1.3 \mathrm{~cm}$. When the signal to noise ratio (SNR) between the small-scale eddy and observation errors is smaller than 1, the eddy would be lost. In addition, some eddies, such as eddy3, are perceived to be in a status of unstably "missed" that only appear in KE-EDt and KE-EDo. The SLA data corresponding to KE-EDs encompassing eddy3 is close to satisfying the criteria of eddy identification. After the procedures of adding observation errors and mapping, the SLA data corresponding to KE-EDo just meets the criteria of eddy identification. It seems to be a transition state between "matched" and "missed". In Figure $4 \mathrm{~d}$, most of these "artifact" eddies seem to have small radii. Sometimes, an eddy in KE-EDt is identified as several smaller eddies in KE-EDs or KE-EDo (Figure 4e). In contrast, if multiple small eddies gather together, they may also be identified as a larger "merged" eddy (Figure 4f). 


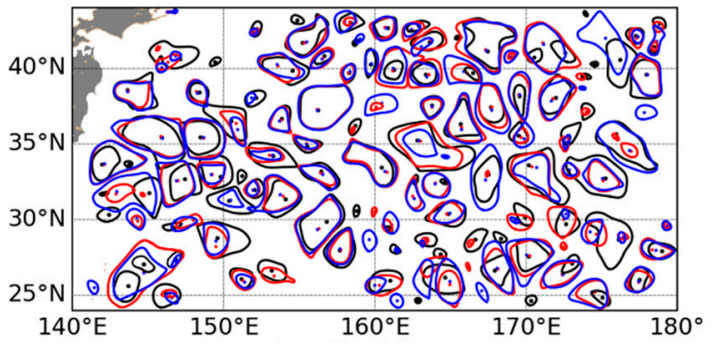

(a) all eddies

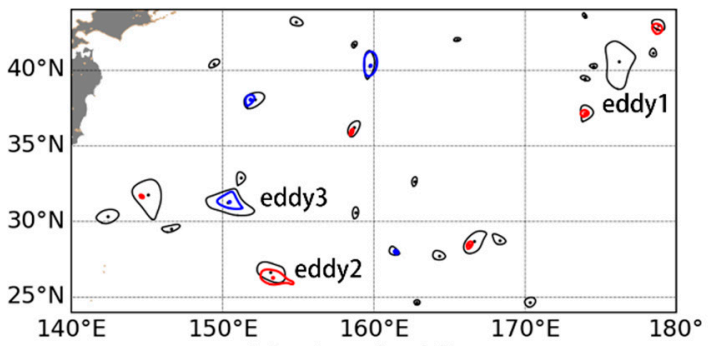

(c) missed eddies

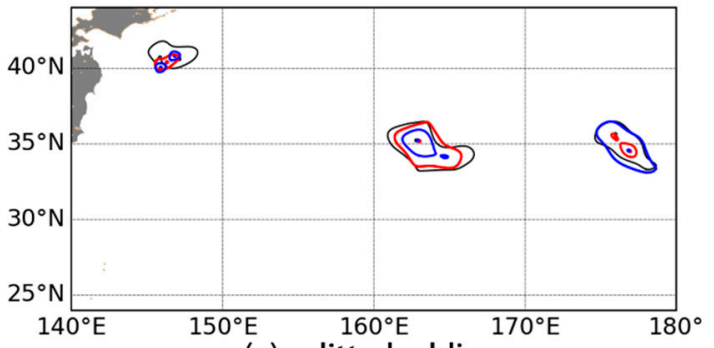

(e) splitted eddies

KE-EDt

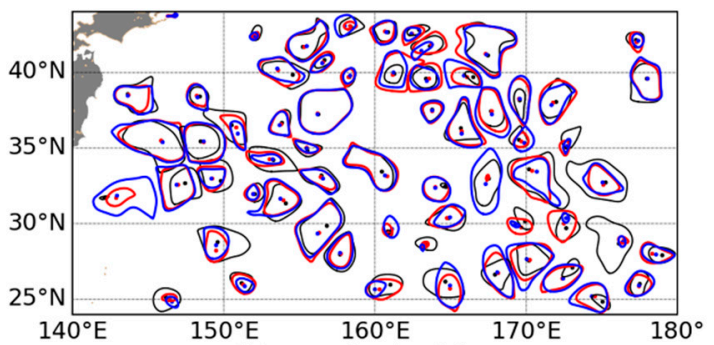

(b) matched eddies

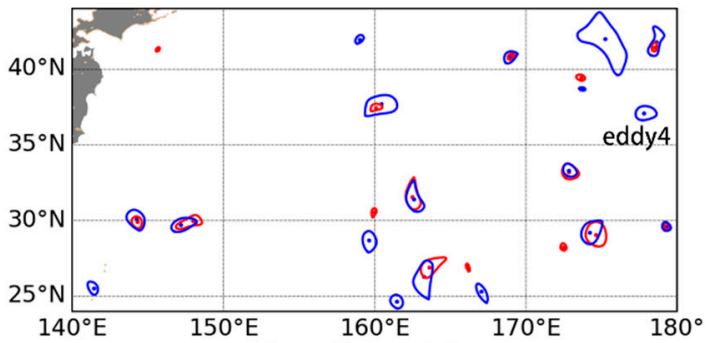

(d) artifact eddies

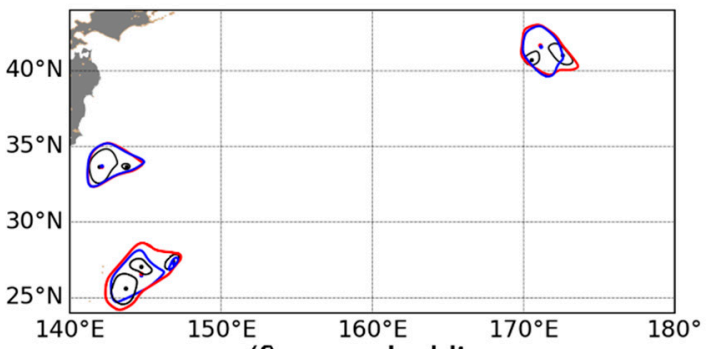

(f) merged eddies

KE-EDs

KE-EDo

Figure 4. Effective perimeters and centers of eddies on 12 January 2015. Black, red, and blue lines represent the effective perimeters of eddies in KE-EDt, KE-EDs, and KE-EDo, respectively. (a) plots the eddies in these three datasets together. $(\mathbf{b}-\mathbf{f})$ show the effective perimeters of eddies labelled with "matched", "missed", "artifact", "split", and "merged", respectively. Besides, those points represent their surface centers.

The total numbers of eddies in KE-EDt, KE-EDs, and KE-EDo are similar (37,090, 35,258, and 35,536, respectively). In the KE region, the proportion of eddies for each CSE type in KE-EDt is shown in Table 3. First, $66 \%$ of eddies can be detected by SWOT, most of which are "matched" eddies, accounting for $61 \%$ of the total. Besides, $2 \%$ (3\%) of the eddies are labelled with "split" ("merged"). Second, a total of $34 \%$ of eddies are lost in KE-EDt. Among them, $6.5 \%$ of eddies (such as eddy2 in Figure 4c) are lost due to SWOT observation errors, corresponding eddies of which cannot be found in KE-EDo. The proportion of eddies in a status of unstably "missed" (such as eddy 3 in Figure $4 \mathrm{c}$ ) is $4 \%$. Subsequently, the remaining $23.5 \%$ of eddies are lost during the procedures of sampling and mapping. In addition, sampling and observation errors of SWOT will lead to the emergence of a mass of "artifact" eddies. A total of 8856 eddies belong to the type of "artifact" in KE-EDs, these eddies are produced due to the OI mapping method. Furthermore, the number of artifact eddies in KE-EDo (9724) is higher than those in KE-EDs, so the SWOT measurements should also produce a small amount of artifact eddies. In the future, it will be a technical challenge to remove the "artifact" eddies in the eddy identification results detected by the SWOT. 
Table 3. The proportion of eddies for each CSE type in KE-EDt.

\begin{tabular}{|c|c|c|c|c|c|}
\hline \multicolumn{3}{|c|}{$\begin{array}{l}\text { Proportion of Detected Eddies } \\
\text { In KE-Edt }(\%)\end{array}$} & \multicolumn{3}{|c|}{$\begin{array}{l}\text { Proportion of Missed Eddies } \\
\text { In KE-Edt }(\%)\end{array}$} \\
\hline \multirow[b]{2}{*}{ Matched } & \multirow[b]{2}{*}{ Split } & \multirow[b]{2}{*}{ Merged } & \multicolumn{3}{|c|}{ Missed } \\
\hline & & & $\begin{array}{l}\text { (Due to Sampling } \\
\text { and Mapping) }\end{array}$ & $\begin{array}{c}\text { (Due to SWOT } \\
\text { Observation Errors) }\end{array}$ & (“Unstably Missed") \\
\hline \multirow[t]{2}{*}{61.0} & 2.0 & 3.0 & 23.5 & 6.5 & 4.0 \\
\hline & 66.0 & & & 34.0 & \\
\hline
\end{tabular}

As shown in Figure 5a, the distributions of the eddy radius for KE-EDs and KE-EDo are similar, but they differ from those of KE-EDt when radii are smaller than $75 \mathrm{~km}$, which can be explained through comparison of Figure 5c,i. The peak of "matched" eddies radius curves (Figure 5c) appears at approximately $75 \mathrm{~km}$, while that of "missed" eddies (Figure $5 \mathrm{i}$ ) is smaller and appears at around $33 \mathrm{~km}$. Smaller eddies are likely to be missed, generating the above distinctions. Meanwhile, the amplitudes of "missed" eddies are chiefly smaller than $12 \mathrm{~cm}$ (Figure 5j). Figure 5e,f present the curves of the "split" eddies with different radii and amplitudes. Many eddies in KE-EDt with radii from 120 to $200 \mathrm{~km}$ may be split into eddies with radii from 20 to $50 \mathrm{~km}$, and a lot of small eddies with amplitude less than $12 \mathrm{~cm}$ are generated in KE-EDs and KE-EDo. Moreover, many eddies with radii from 20 to $50 \mathrm{~km}$ would merge into ones with the radii from 120 to $200 \mathrm{~km}$ as presented in Figure $5 \mathrm{~g}$. However, numerous "artifact" eddies with small radii and amplitudes are generated (Figure 5k-1), which are mainly produced during the mapping process. Furthermore, their distributions are similar to those of "missed" eddies in KE-EDt.

According to Table 3 and Figure 5, the proportion of "matched" and "missed" eddies is higher than that of other types. To investigate the ratio of the number of "matched" and "missed" eddies to the total number of eddies in KE-EDt with disparate radii and amplitudes, we introduce two variables $r_{n_{-} r}$ and $r_{n_{-} a}$, which can be calculated by Formulas (7) and (8). $N_{C S E_{-} r}$ and $N_{\text {total_ } r}$ are the number of one CSE and all eddies on a radius. Similarly, $N_{C S E \_a}$ and $N_{\text {total } \_a}$ are the number of one CSE and all eddies on an amplitude.

$$
\begin{aligned}
& r_{n \_r}=N_{C S E_{-} r} / N_{t o t a l \_a} \\
& r_{n \_a}=N_{C S E \_a} / N_{t o t a l \_a}
\end{aligned}
$$

The results of $r_{n \_r}$ and $r_{n_{-} a}$ have been clearly shown in Figure 6. These two variables of "missed" eddies continue to diminish with the increase of the radius and amplitude (red lines), while the ratio of "matched" eddies show the opposite trend (black lines). Although Wang et al. [13] suggested that the SWOT scales in KE region would reach between 25 and $40 \mathrm{~km}$ varying seasonally, over $70 \%$ of the small eddies whose radii are between 12 and $20 \mathrm{~km}$ are lost. Among them, more than $40 \%$ of eddies would be degraded by insufficient temporal sampling and mapping process at these scales (red dashed line in Figure 6a). When the radius is $\sim 50 \mathrm{~km}$, the $r_{n_{-} r}$ of "matched" and "missed" eddies is equal, both of which are about $50 \%$. Besides, the loss rate of eddies with radius greater than $100 \mathrm{~km}$ is less than $20 \%$. In addition, the red curve in Figure $6 \mathrm{~b}$ reveals that the loss rate of eddies with small amplitude $(<2 \mathrm{~cm})$ is close to $45 \%$, in which more than $30 \%$ of eddies are lost due to sampling and mapping (dashed red line in Figure 6b). When the amplitude is greater than $14 \mathrm{~cm}$, the loss rate of eddies is less than $20 \%$. 

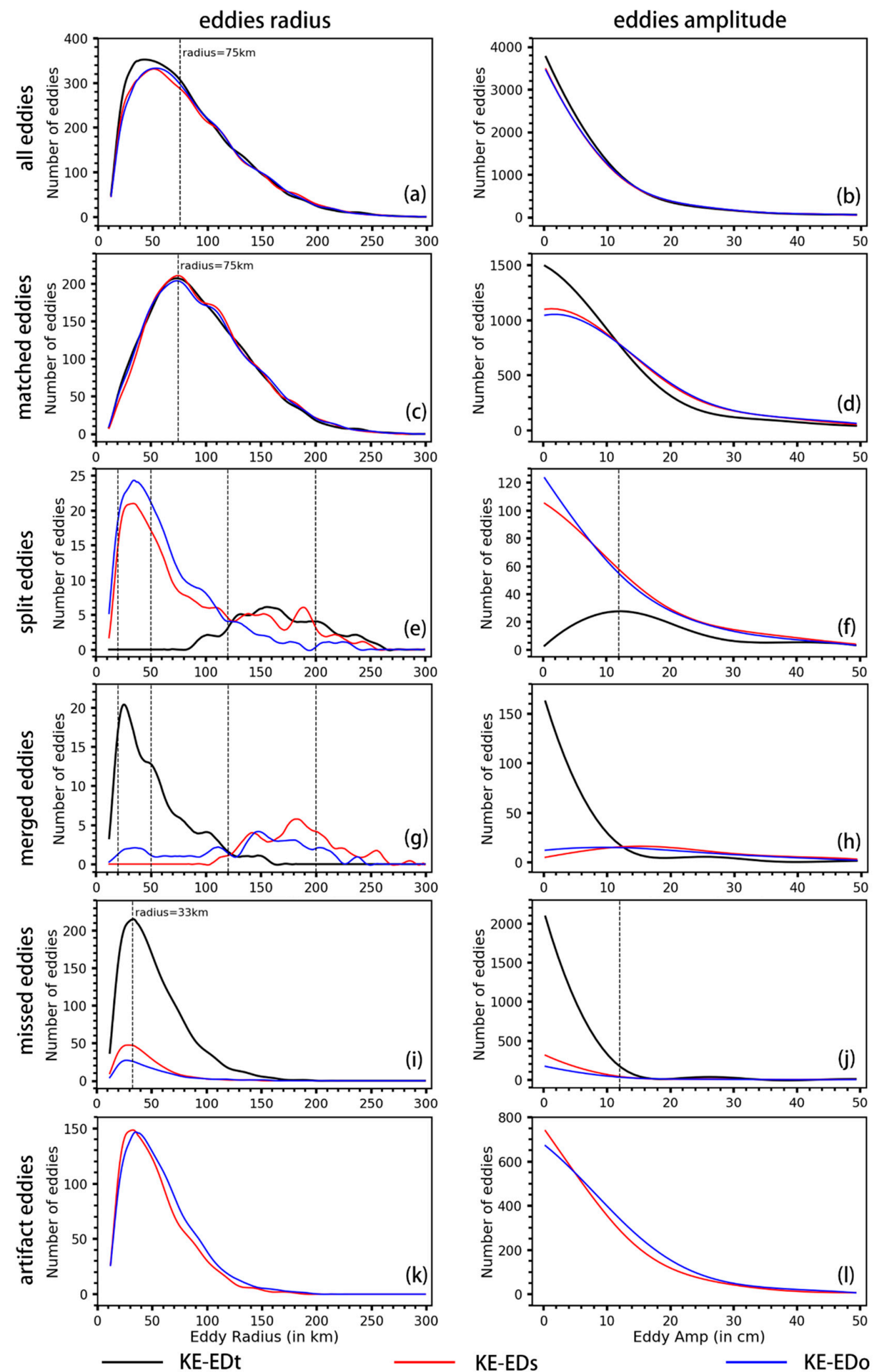

Figure 5. Histograms of the eddy radius (left) and amplitude (right) for all datasets (the black, red and blue lines stand for KE-EDt, KE-EDs, and KE-EDo, respectively) in the Kuroshio Extension (KE) region. $(\mathbf{a}, \mathbf{b})$ show the histograms of all eddies in three datasets. $(\mathbf{c}, \mathbf{d}),(\mathbf{e}, \mathbf{f}),(\mathbf{g}, \mathbf{h}),(\mathbf{i}, \mathbf{j})$, and $(\mathbf{k}, \mathbf{l})$ correspond to the eddies of "matched", "split", "merged", "missed", and "artifact", respectively. The values marked with dashed lines will be discussed in detail. 

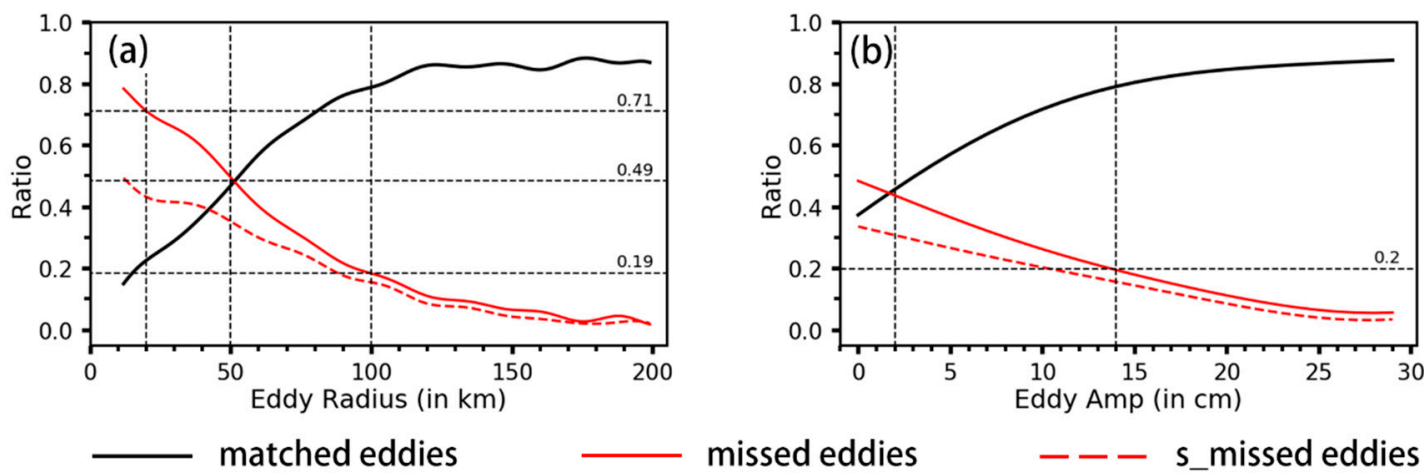

missed eddies

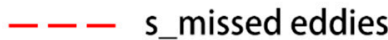

Figure 6. The ratio of the number of "matched" eddies (the black line) and "missed" eddies (the red line) to the total number of eddies in KE-EDt with the radius (a) and amplitude (b). The red dashed lines indicate the ratio of "missed" eddies due to the sampling and mapping process. The values marked with black dashed lines will be discussed in detail.

Furthermore, we have analyzed the influence of errors on "matched" eddies. An eddy $e_{\text {tmatched }}$ is labelled with "matched" in KE-EDt, and a corresponding eddy can be found in KE-EDs and KE-EDo, namely $e_{\text {smatched }}$ and $e_{\text {omatched }}$, respectively. Through comparing the variations of the parameters (radius and amplitude) of $e_{\text {tmatched }}$ and $e_{\text {smatched }}$, the influence of sampling on "matched" eddies is derived. Similarly, the comparison between $e_{\text {smatched }}$ and $e_{\text {omatched }}$ reflects the influence of observation errors on "matched" eddies. The horizontal coordinate of a point in Figure 7a (Figure 7c) represents the radius (amplitude) of $e_{\text {tmatched }}$, and the vertical coordinate is the radius (amplitude) of $e_{\text {smatched }}$. Likewise, the horizontal coordinate of a point in Figure $7 \mathrm{~b}$ (Figure 7d) denotes the radius (amplitude) of $e_{\text {smatched }}$, and the vertical coordinate is the radius (amplitude) of $e_{\text {omatched }}$. Red lines represent the average radius $\left(R_{\text {avg }}\right)$ or average amplitude $\left(A_{\text {avg }}\right)$ at the horizontal coordinate $R$ (radius) or $A$ (amplitude), and green lines refer to the ratio of them. $r_{\text {radius }}$ is the ratio of $R_{\text {avg }}$ to $R$, and $r_{\text {amplitude }}$ is the ratio of $A_{\text {avg }}$ to $A$, whose calculation formulas are presented as follows.

$$
\begin{gathered}
r_{\text {radius }}=R_{\text {avg }} / R \\
r_{\text {amplitude }}=A_{\text {avg }} / A
\end{gathered}
$$

The red line in Figure 7a suggests that when the radius $\mathrm{R}$ of $e_{\text {tmatched }}$ is smaller (larger) than 88 $\mathrm{km}$, the average radius $R_{a v g}$ of $e_{\text {smatched }}$ is larger (smaller) than $R$. The green line in Figure 7a shows the $r_{\text {radius }}$ between $e_{\text {smatched }}$ and $e_{\text {tmatched }}$. When $R$ is smaller than $50 \mathrm{~km}, r_{\text {radius }}$ is greater than 1 , indicating that the eddy with a small radius would likely become larger after procedures of sampling and mapping. The green line in Figure $7 \mathrm{c}$ also shows that when the amplitudes of eddies in KE-EDt are small (amplitude less than $11 \mathrm{~cm}$ ), the $r_{\text {amplitude }}$ is larger than 1 . The variation of the green line in Figure $7 \mathrm{~b}$ (Figure 7d) is similar to that in Figure 7a (Figure 7c), and the observation errors result in a large $r_{\text {radius }}$ and $r_{\text {amplitude }}$ of small eddies (radius smaller than $50 \mathrm{~km}$ or amplitude less than $11 \mathrm{~cm}$ ). For eddies with radii greater than $50 \mathrm{~km}$ or amplitudes greater than $11 \mathrm{~cm}$, both the $r_{\text {radius }}$ and $r_{\text {amplitude }}$ are close to 1 . From the comparison of the data density distribution presented in Figure $7 \mathrm{a}, \mathrm{b}$, the data near the black line in Figure 7a is found to be sparser, with similar comparison results derived from the data density distributions in Figure 7c,d. It indicates that compared with the observation errors, the variance of the eddy radius and amplitude difference value caused by sampling error is larger. The correlation coefficient (CORR) in Figure $7 \mathrm{~b}$ (Figure $7 \mathrm{~d}$ ) is $0.84(0.93)$ which is much larger than 0.66 (0.79) in Figure 7a (Figure 7c). It is suggested that variations of eddies caused by procedures of sampling and mapping are more evident than those triggered by observation errors. 

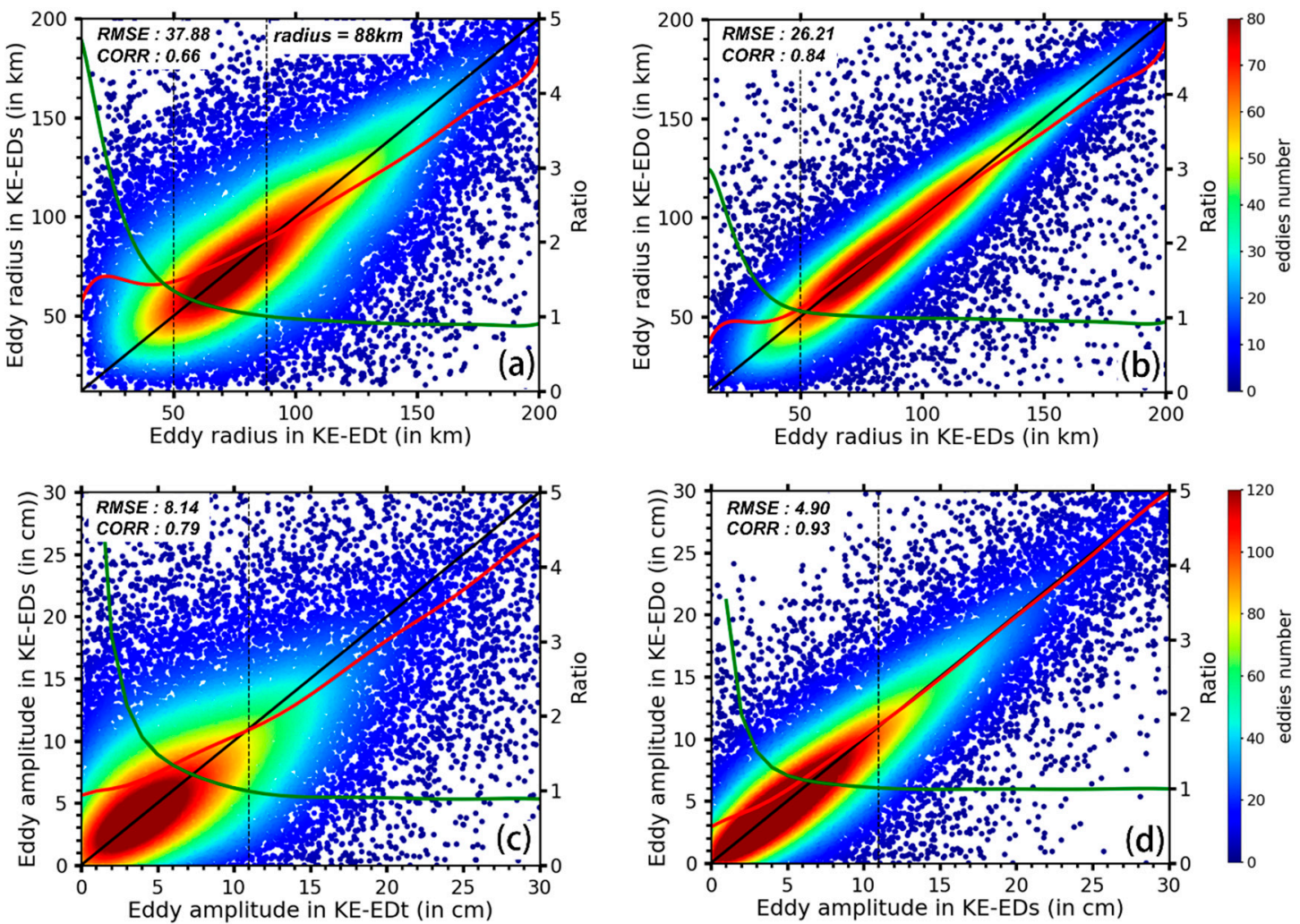

Figure 7. The scatter diagram of "matched" eddies: (a)/(c) are the radius/amplitude of "matched" eddies in KE-EDs versus corresponding eddies in KE-EDt, and (b)/(d) show the radius/amplitude of "matched" eddies in KE-EDo versus corresponding eddies in KE-EDs. The color shows the data density. The black lines are the diagonal. The red lines show the average radius (amplitude). The green lines show the average ratio $\left(r_{\text {radius }}\right.$ or $\left.r_{\text {amplitude }}\right)$. The "CORR" represents the correlation coefficient. The values marked with dotted lines will be discussed in detail.

The mean structures of eddies with different groups are shown in Figure 8 and all closed to standard circles. The average radius of the "matched" eddies (Figure 8a) in KE-EDt is significantly larger than that of the "missed" eddies (Figure 8b), which is consistent with that the eddies with smaller radii are more likely to be lost (Figure 6a, red lines). Two major patterns can be revealed from Figure $8 \mathrm{c}$,d. One is that the lines in Figure $8 \mathrm{c}$ (Figure $8 \mathrm{~d}$ ) almost overlap, indicating that the mean structures of eddies in the three datasets KE-EDt, KE-EDs, and KE-EDo are similar. The other is that there is no obvious difference between the mean structures of cyclonic and anticyclonic eddies. 

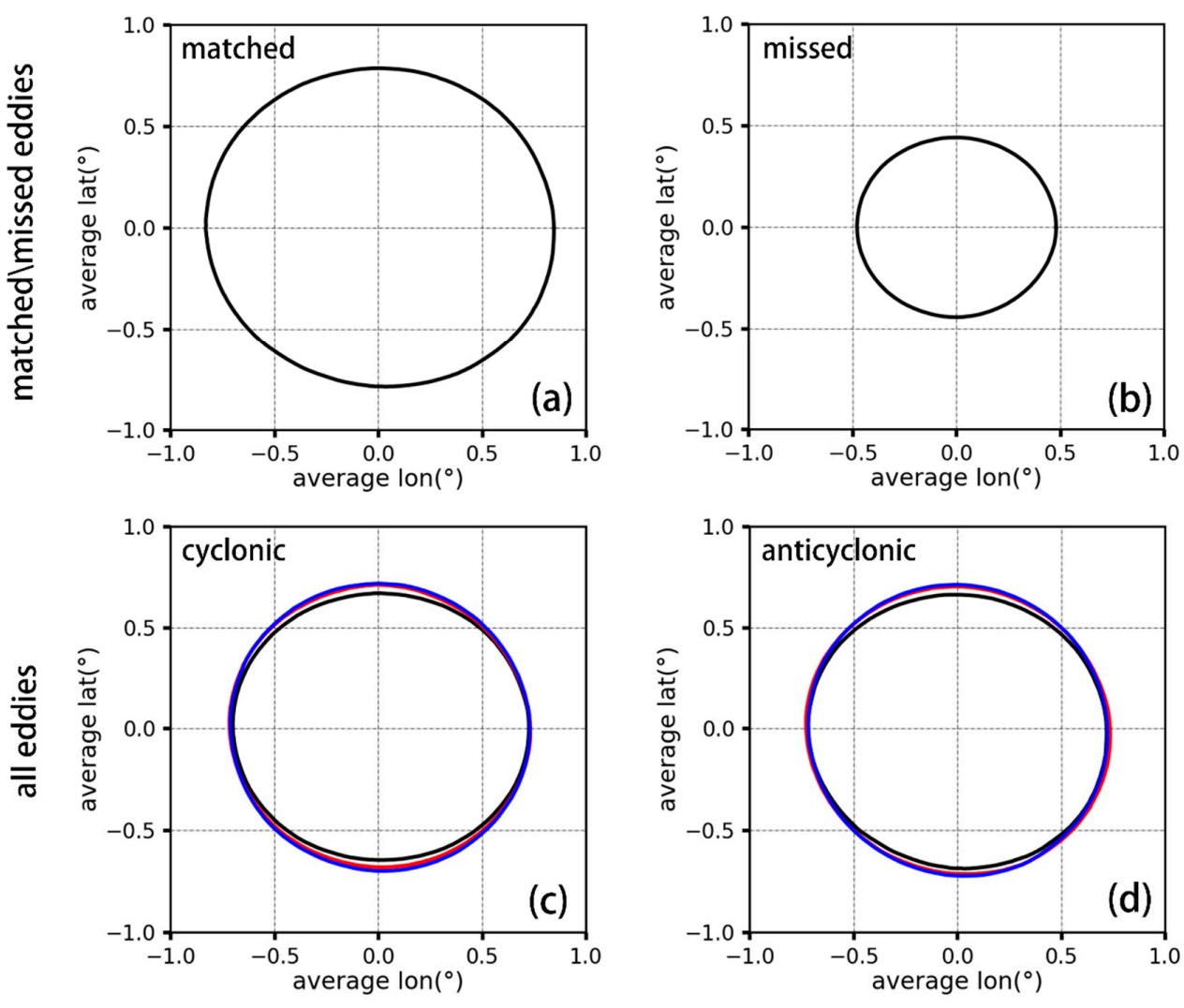

KE-EDt

KE-EDs

KE-EDo

Figure 8. The mean structures of eddies. (a)/(b) is the mean structure of all "matched" / "missed" eddies. (c) is the mean structure of cyclonic eddies for all eddies in the KE-EDo (black line), KE-EDs (red line) and KE-EDo (blue line). (d) shows the mean structure of the anticyclonic eddies corresponding to (c).

\section{Discussion}

\subsection{Comparison with OSSEs in the South China Sea (SCS)}

This study conducts the OSSEs in the SCS region using HYCOM data. Considering the latitude range of the SCS region and the criteria of the eddy identification algorithm, the radius of an eddy should be larger than $20 \mathrm{~km}$. Consequently, three eddy datasets named SCS-EDt, SCS-EDs, and SCS-EDo are derived, the total numbers of eddies in SCS-EDt, SCS-EDs, and SCS-EDo are 14,037, 13,801 , and 14,513, respectively. The proportion of eddies for each CSE type in SCS-EDt is shown in Table 4.

Table 4. The proportion of eddies for each CSE type in SCS-EDt.

\begin{tabular}{cccccc}
\hline \multicolumn{2}{c}{$\begin{array}{c}\text { Proportion of Detected Eddies } \\
\text { In SCS-Edt (\%) }\end{array}$} & \multicolumn{3}{c}{$\begin{array}{c}\text { Proportion of Missed Eddies } \\
\text { In SCS-Edt (\%) }\end{array}$} \\
\hline Matched & Split & Merged & \multicolumn{3}{c}{ Missed } \\
\cline { 3 - 6 } & & $\begin{array}{c}\text { (Due to Sampling } \\
\text { and Mapping) }\end{array}$ & $\begin{array}{c}\text { (Due to SWOT } \\
\text { Observation Errors) }\end{array}$ & (“Unstably Missed”) \\
\hline 58.5 & 0.5 & 1.0 & 29.0 & 6.0 & 5.0 \\
\hline & 60.0 & & & 40.0 & \\
\hline
\end{tabular}

The percentage of "matched" eddies, accounting for $58.5 \%$, is also the highest in SCS-EDt, which is $2.5 \%$ less than that in KE-EDt (61\% in Table 3). However, the loss rate of eddies in the SCS region (40\% in Table 4) is significantly higher than that in the KE region, which is $6 \%$ more than that in KE-EDt (34\% in Table 3). Therefore, the loss rate of eddies may be quite disparate in two different regions, and 
it is related to the distribution of the eddy properties (radius and amplitude) and the sampling density of SWOT. Figure 9 shows the distribution of the eddy radius and amplitude in KE-EDt and SCS-EDt.
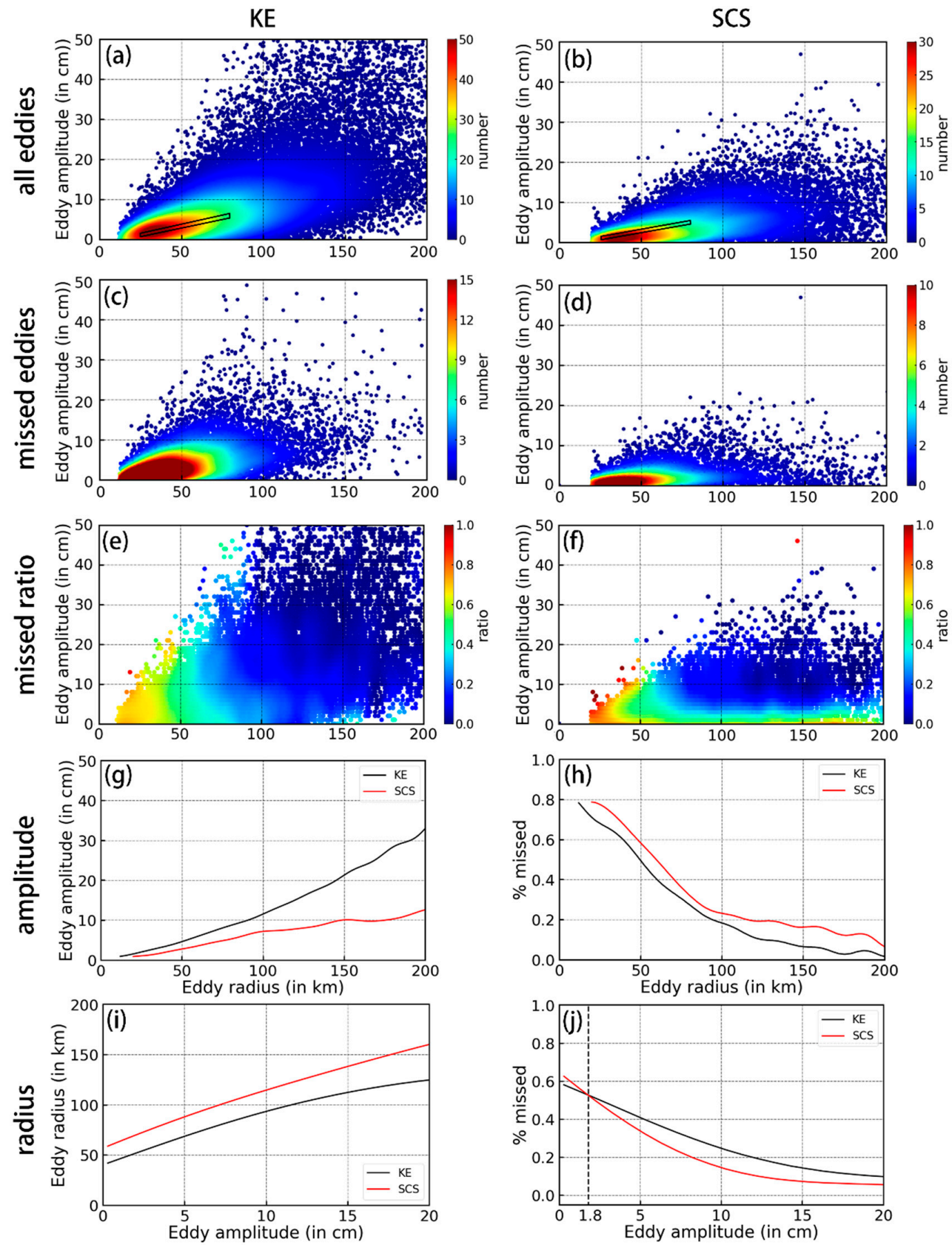

Figure 9. The scatter diagram of eddy properties in KE-EDt (left) and SCS-EDt (right). (a,b) are the radii and amplitudes of all eddies, with the color representing the data density. The "missed" eddies are shown in (c,d). (e,f) are the ratio of the "missed" eddies to all eddies. The black line (KE-EDt) and the red line (SCS-EDt) in (g)/(i) represent the average amplitude/radius of all eddies. (h) and (j) represents the average ratio of "missed" eddies.

As shown in Figure 9a,b, the amplitudes of eddies in the KE are significantly greater than that in the SCS. A large number of eddies in the KE have an amplitude greater than $30 \mathrm{~cm}$, while the amplitudes of eddies in SCS are mostly less than $30 \mathrm{~cm}$. Figure 9c,d demonstrate that eddies with smaller radii and amplitudes (the radius less than $50 \mathrm{~km}$ and amplitude less than $5 \mathrm{~cm}$ ) are more apt to be lost. According to Figure 9e,f, the loss rate of eddies gradually decreases with the increase of radius and amplitude. Statistically, the average amplitude of eddies in the SCS is smaller than that in the 
KE region (Figure 9g), and the corresponding loss rate is larger (Figure 9h). In contrast, the average radius of eddies in the SCS is larger than that in the KE region (Figure 9i), and the loss rate is almost smaller (Figure 9h). When the amplitude is smaller than $1.8 \mathrm{~cm}$ (dashed line in Figure 9j), the reversed situation appears. This should be caused by the smaller sampling density of SWOT in the SCS.

Compared with the KE region (at higher latitudes), the average revisit time of SWOT in the SCS (at lower latitudes) is longer, and the sampling density (number of observations per cycle) is smaller [35]. Figure 10 presents that the average sampling density of SWOT in the KE region (2.0) is bigger than that in the SCS (1.6) during a period (21 days) of SWOT. The average revisit time in the KE is roughly 10.5 days, and it is nearly 13 days in the SCS. The distances measured along latitude between two adjacent ground tracks in the KE and SCE are in the range of 96-127 km and 125-139 km, respectively.
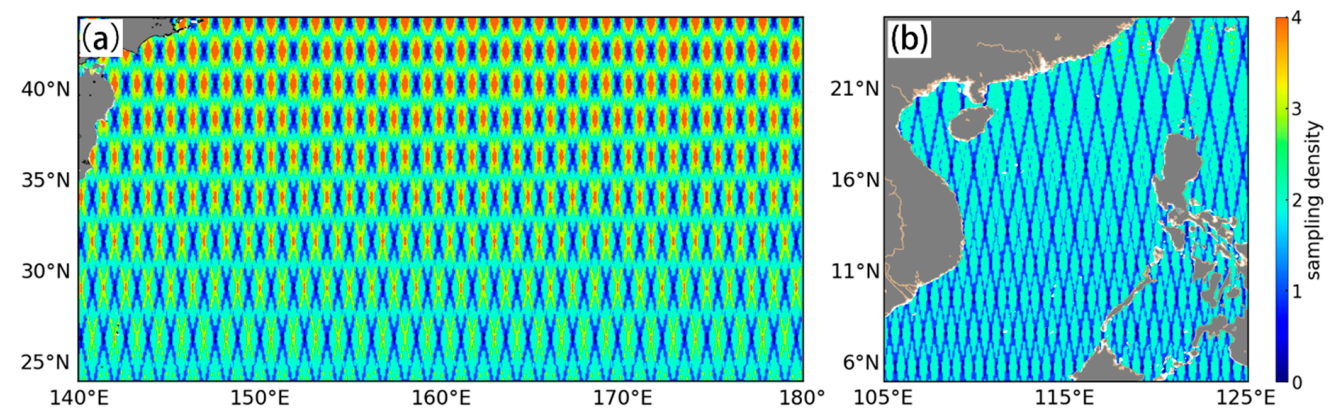

Figure 10. Sampling density of Surface Water and Ocean Topography (SWOT) within a period (21 days).

(a) Kuroshio Extension (KE) region. (b) South China Sea (SCS) region.

For a better understanding of the impact of sampling density on the loss rate of eddies, two sub-datasets with similar characteristics are selected from KE-EDt and SCS-EDt. The radius and amplitude range of these two sub-datasets are shown the in red shading area of Figure 11a and also marked with black rectangles in Figure 9a,b. Data density of the sub-datasets is relatively large, which ensures the reasonable statistical results. The curves of the average amplitude of eddies in the two sub-datasets, as shown by the red and black lines in Figure 11a, mostly overlap, which indicates their similar properties distributions. As shown in Figure 11b, the eddy loss rate of the sub-dataset in the SCS (red line) is larger than that in the KE region (black line), especially for eddies with radii of $25-40 \mathrm{~km}$, which has the rate variance of about $7 \%$. It is noteworthy that the difference of the eddy loss rate between these two sub-datasets is mainly attributed to the different sampling density of SWOT in the KE region and the SCS region.
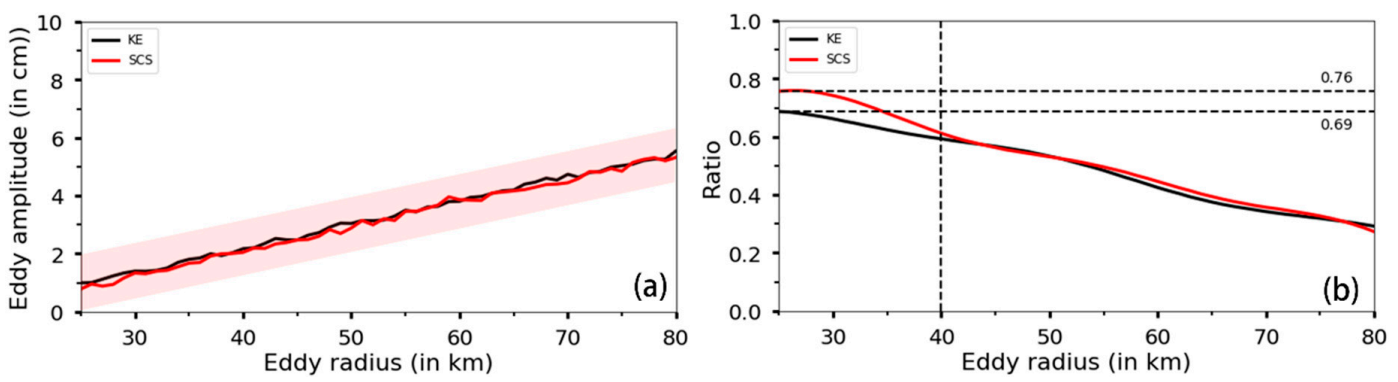

Figure 11. Comparison of the loss rate of eddies between the two sub-datasets with similar characteristics selected from KE-EDt and SCS-EDt. (a) The black line (KE) and the red line (SCS) are the average amplitudes; the red shading shows the selected range of the radius and amplitude. (b) shows the eddy loss rate of the two sub-datasets. The black line stands for KE and red line stands for SCS.

\subsection{The Influence of SWOT Errors on Small Scale Eddies (with Radius Scales of $\sim 10 \mathrm{~km}$ )}

When the spatial scale is smaller than $15 \mathrm{~km}$, the ocean decorrelation time is below one day, which is much shorter than the revisit time of SWOT [17]. The errors caused by temporal interpolation 
in mapped SSH data will make it difficult to reconstruct the sub-mesoscale eddies which are not directly sampled by SWOT. In order to clearly understand the influence of SWOT errors on the observation results of small scale eddies, the OSSEs without the OI process have been conducted based on high-resolution ROMS model data and the software of the SWOT simulator [12]. As shown in Figure 12a,b, two eddies are selected on the single swath of pass 095 in cycle 1, with their radii being about $10 \mathrm{~km}$. Cyclone eddy in the north, named SCE, whose amplitude is about $1.5 \mathrm{~cm}$. Furthermore, the anticyclone eddy in the south, named SAE, has the amplitude about $1.0 \mathrm{~cm}$. In this study, these two eddies are repeatedly observed for 100 times by the SWOT simulator and the SWOT-like SSH fields are synthesized. In these 100 repeated observations, the input model SSH fields are the same, but the error fields are random and different. Two examples of SWOT-like SSH (model plus errors) are selected randomly and plotted in the right sub images of Figure 12d,e. Similar to Gaultier et al. [12], the SWOT-like SSH data are filtered with a spatial optimal interpolation locally on each swath, so that the geostrophic velocity can be well revealed, as shown in the middle of Figure 12d,e.
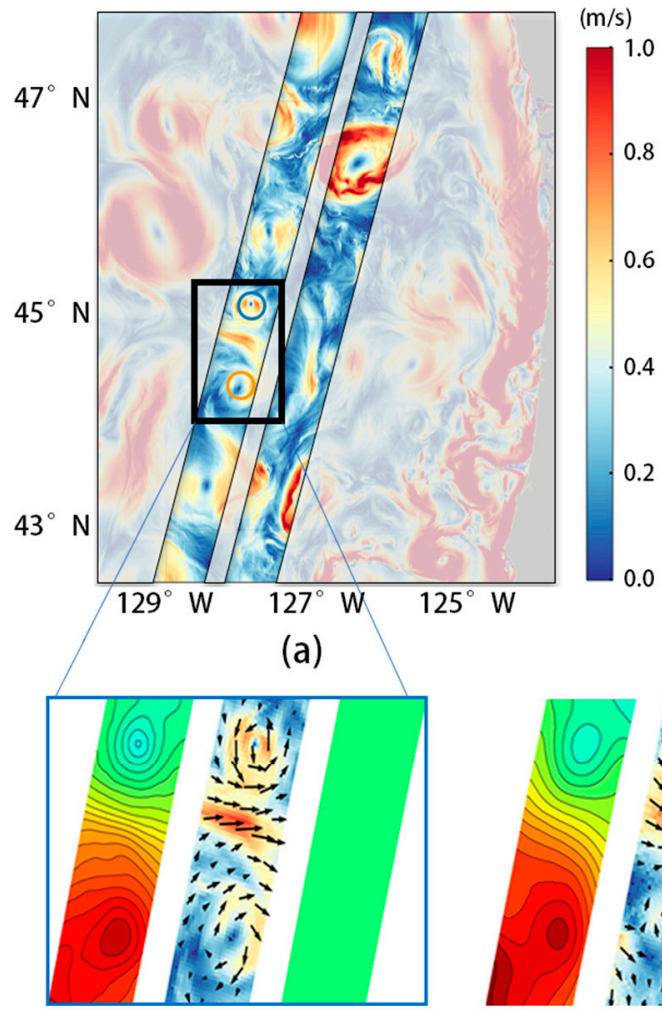

(c)

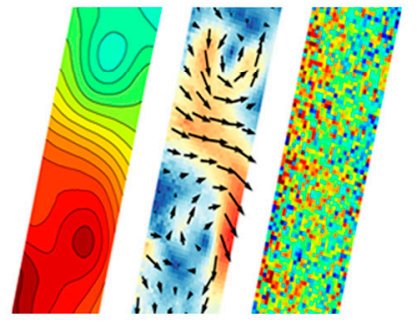

(d)

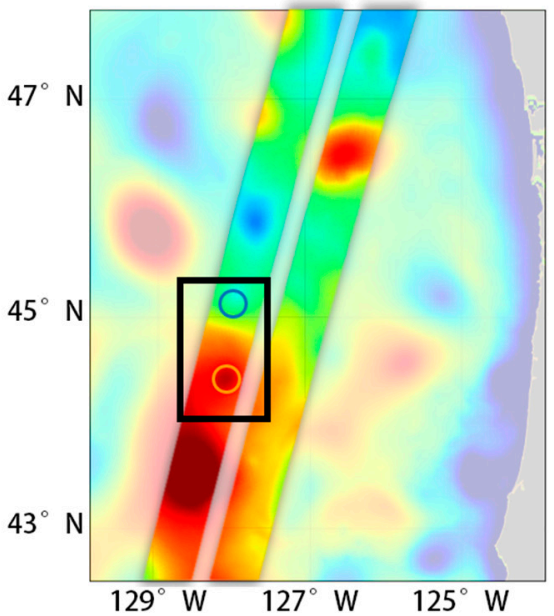

(b)

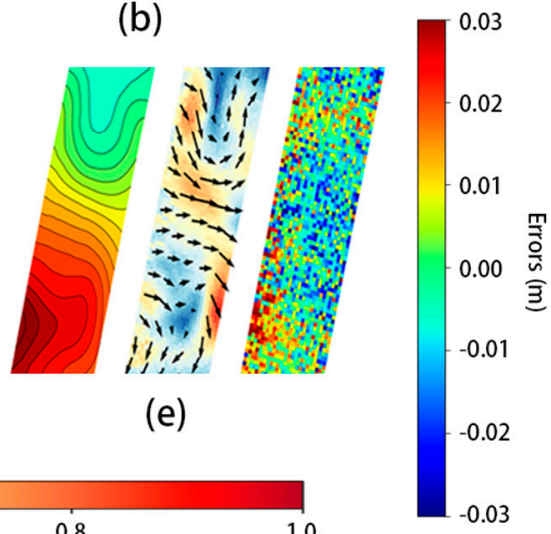

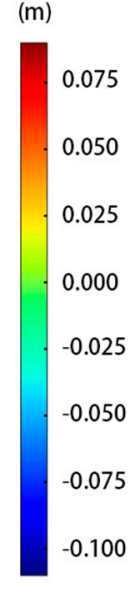

.075

025

000

.025

075

0.100

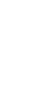


- The eddy center is visible in the geostrophic velocity field;

- The rotating structure is visible in the geostrophic velocity field;

- $\quad$ The SSH contour is closed in the SSH field.

On the basis of this visual eddy identification method, we classify these observation results. The loss rate of SCE is $16 \%$, and that of SAE is $24 \%$. The amplitude of SCE is $0.5 \mathrm{~cm}$ larger than that of SAE, while the loss rate of SCE is $8 \%$ less than that of SAE. Moreover, a one-dimensional (1D) power spectrum of the sampled SSH is computed along the track. The power spectra are averaged across the swath and plotted in Figure 13. The observation SSH spectrum (the black line) follows the true SSH spectrum (the red line) until $54 \mathrm{~km}$ (dashed line in Figure 13). Compared with the power spectrum of observation, the spectrum of the filtered observation (the blue line) is basically the same as the one in the model SSH, indicating that filtering can indeed improve the resolution to $20 \mathrm{~km}$. However, the fact is that more than $16 \%$ of the filtered sub-mesoscale eddies with radii of $\sim 10 \mathrm{~km}$ would be missed. Therefore, the spectrum is difficult to reveal the eddy detection results directly, and it is essential to conduct these special OSSEs.

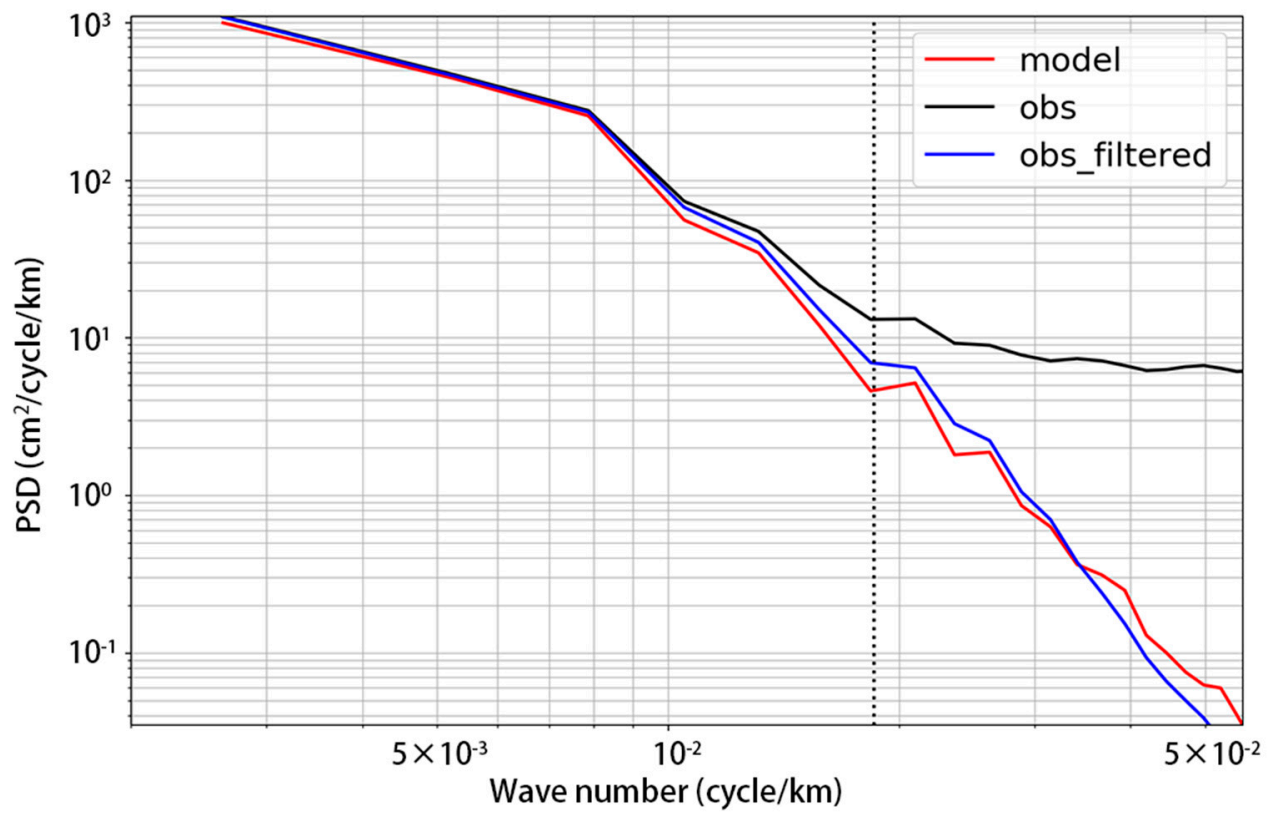

Figure 13. Power spectrum of the true SSH (red), the observation SSH (black), and the filtered observation SSH (blue).

\subsection{Underlying Assumptions and Biases}

The results of OSSEs implemented in the regions of KE and SCS make sense under several assumptions, including employing HYCOM data, SWOT error budget, OI based mapping, and an SLA contour based eddy identification algorithm. These assumptions would lead to overestimating or underestimating the eddy detection capabilities of SWOT. First, the HYCOM SSH data we used do not have tides. Therefore, the effect of internal tides on SWOT measurements has not been considered. When the spatial scale decreases to tens of kilometers, the SSH variance shifts from balanced-motion (eddy) dominant to wave dominant. If the SWOT scale $(L s)$ is larger than the transition wavelength $(L t)$, it is difficult to separate the signals between internal tides and eddies [36]. From the results of Wang et al. [13], the mean Ls is smaller than the mean $L t$ in the KE and SCS regions. However, during February-April, the $L s$ is larger than $L t$ in the north of KE, indicating that proportion of "missed" eddies detected by future SWOT will be increased in winter. Second, the observation errors, especially the Sea-State Bias (SSB) related to surface waves, are under-estimated by the error document and SWOT simulator. Bai et al. [37] analyze the impact of sea-state on 2D altimeter measurement errors, 
and they find that the SSH would be significantly underestimated due to velocity bunching. However, there is no sophisticated error model for SSB to use here. The actual SSB would increase the proportion of "missed" eddies. Third, different mapping techniques would generate various results. Traditional OI method is difficult to adapt to the SWOT sampling data, and some eddies in EDs and EDo may be deformed and missed due to the limitation of the statistical OI. At present, although there is no established method for SWOT yet, some new mapping methods, such as dynamical interpolation [38] and back-and-forth nudging approach [39], are proposed successively. Besides, the future SSH maps should be a combination of both SWOT and the existing nadir satellite datasets. The proportion of "missed" eddies should decrease through conducting an improved mapping method of multi-satellite altimeter data. Forth, eddy identification algorithm also impacts the results. The SLA contour based methods $[3,30]$ are the most popular at present. These methods are proved to be effective in identifying mesoscale eddies, while some improved methods need to be developed to identify smaller scale eddies. The results of the present study are derived only on the basis of current eddy identification technology. Finally, compared with the actual eddy detection capabilities of upcoming SWOT, the simulation results of this study would be biased inevitably due to the limitation of existing technologies. For the influences of SWOT sampling and errors on eddy observation, this study has explored as much as possible through combining current typical model data and technologies.

\section{Conclusions}

In this study, three OSSEs and five types of CSE are designed to characterize the influences of SWOT sampling and errors on ocean eddy detection results. The results of OSSEs implemented in the KE region indicate that the "matched" eddies account for the highest proportion (61\%) and the proportion of "missed" eddies is as high as 34\%. Among them, 23.5\% are lost due to insufficient temporal sampling; $6.5 \%$ are missed owing to SWOT errors; $4 \%$ of eddies are considered as "unstably missed". The relative "missed" rate is employed to compare the SWOT capabilities to detect eddies with different radii. When the radii are greater than $100 \mathrm{~km}$, the relative "missed" rates of the eddies are less than $20 \%$. Contrastingly, more than $70 \%$ of the small eddies with radii between 12 and $20 \mathrm{~km}$ are lost. In addition, after the procedures of simulated observation, mapping and eddy identification, numerous "artifact" eddies are unexpectedly generated in the KE-EDs and KE-EDo datasets.

This study implemented another similar experiment for comparison in the SCS. The results demonstrate that the proportion of "missed" eddies in the SCS is $40 \%$, which is $6 \%$ more than that in the KE region. Two exists reasons: on the one hand, the smaller average radii and amplitudes of eddies add to the difficulty of detection for eddies in the SCS. On the other hand, because the average sampling density of SWOT in the SCS (a zone between $5^{\circ} \mathrm{N}$ and $25^{\circ} \mathrm{N}$ ) is smaller than that in the KE region (a zone between $24^{\circ} \mathrm{N}$ and $44^{\circ} \mathrm{N}$ ), the less temporal sampling leads to the loss of more eddies.

To further analyze the influence of SWOT errors on smaller-scale eddies, this study conducts the third simulation experiment, in which two eddies are observed for 100 times on the basis of the SWOT simulator and high-resolution ROMS model data. In these 100 repeated simulation observations, the SWOT error fields are random and different. The cyclonic eddy with a larger amplitude $(1.5 \mathrm{~cm}) \mathrm{can}$ be detected 84 times, while the anticyclonic eddy with a smaller amplitude $(1.0 \mathrm{~cm})$ can be observed the characteristics of eddy only 76 times. Therefore, relatively large amplitude of the sub-mesoscale eddy can have large probability of being detected by SWOT, but it is difficult to ensure the all-time detection.

SWOT will certainly offer new opportunities to observe the sub-mesoscale eddies on a global view. However, the simulation results in this study uncover that some challenges will surface, such as the difficulty of identifying the sub-mesoscale eddies and the emergence of numerous "artifact" eddies, etc. In the future, it is necessary to design improved sub-mesoscale eddy identification criteria, and the "artifact" eddies may be reduced through dynamic interpolation mapping technology. 
Author Contributions: Conceptualization, C.M. and G.C.; formal analysis, C.M., X.G. and H.Z.; funding acquisition, G.C.; methodology, C.M., X.G. and H.Z.; software, X.G.; investigation, C.M. and X.G.; resources, J.D.; data curation, X.G.; writing-original draft preparation, X.G. and H.Z.; writing-review and editing, C.M.; visualization, X.G. and H.Z.; supervision, G.C.; project administration, G.C. All authors have read and agreed to the published version of the manuscript.

Funding: This research was funded by Youth Program of National Natural Science Foundation of China: No. 41906155, the Key Research and Development Program of Shandong Province: No. 2019GHZ023, and the Fundamental Research Funds for the Central Universities: No. 201762005, the National Key Scientific Instrument and Equipment Development Projects of National Natural Science Foundation of China: No. 41527901.

Acknowledgments: We are very grateful to the simulation software provided by the SWOT team and the free data provided by the HYCOM Center [21]. We would like to thank the staff in the editorial office and the authors who contributed to the paper.

Conflicts of Interest: The authors declare no conflict of interest.

\section{References}

1. Dong:, C.; McWilliams, J.C.; Liu, Y.; Chen, D. Global heat and salt transports by eddy movement. Nat. Commun. 2014, 5, 3294. [CrossRef] [PubMed]

2. Johnson, K.S.; Riser, S.C.; Karl, D.M. Nitrate supply from deep to near-surface waters of the north pacific subtropical gyre. Nature 2010, 465, 1062-1065. [CrossRef] [PubMed]

3. Chelton, D.B.; Schlax, M.G.; Samelson, R.M. Global observations of nonlinear mesoscale eddies. Prog. Oceanogr. 2011, 91, 167-216. [CrossRef]

4. Chelton, D.B.; Gaube, P.; Schlax, M.G.; Early, J.J.; Samelson, R.M. The influence of nonlinear mesoscale eddies on near-surface oceanic chlorophyll. Science 2011, 334, 328-332. [CrossRef]

5. Chen, G.; Han, G.; Yang, X. On the intrinsic shape of oceanic eddies derived from satellite altimetry. Remote Sens. Environ. 2019, 228, 75-89. [CrossRef]

6. Zhang, Z.; Wang, W.; Qiu, B. Oceanic mass transport by mesoscale eddies. Science 2014, 345, 322-324. [CrossRef]

7. Faghmous, J.H.; Frenger, I.; Yao, Y.; Warmka, R.; Lindell, A.; Kumar, V. A daily global mesoscale ocean eddy dataset from satellite altimetry. Sci. Data 2015, 2, 150028. [CrossRef]

8. Fu, L.-L.; Chelton, D.B.; Le Traon, P.-Y.; Morrow, R. Eddy dynamics from satellite altimetry. Oceanography 2010, 23, 14-25. [CrossRef]

9. Chelton, D.B.; Schlax, M.G. The accuracies of smoothed sea surface height fields constructed from tandem satellite altimeter datasets. J. Atmos. Ocean. Technol. 2003, 20, 1276-1302. [CrossRef]

10. Cédric, P.C.; Patrice, K. Can oceanic submesoscale processes be observed with satellite altimetry? Geophys. Res. Lett. 2010, 37, 707-716.

11. Lévy, M.; Iovino, D.; Resplandy, L.; Klein, P.; Madec, G.; Tréguier, A.M.; Masson, S.; Takahashi, K. Large-scale impacts of submesoscale dynamics on phytoplankton: Local and remote effects. Ocean Model. 2012, 43, 77-93. [CrossRef]

12. Gaultier, L.; Ubelmann, C.; Fu, L.-L. The challenge of using future SWOT data for oceanic field reconstruction. J. Atmos. Ocean. Technol. 2015, 33, 119-126. [CrossRef]

13. Wang, J.; Fu, L.L.; Torres, H.S.; Chen, S.; Qiu, B.; Menemenlis, D. On the spatial scales to be resolved by the surface water and ocean topography Ka-band radar interferometer. J. Atmos. Ocean. Technol. 2019, 36, 87-99. [CrossRef]

14. Amores, A.; Jordà, G.; Arsouze, T.; Le Sommer, J. Up to what extent can we characterize ocean eddies using present-day gridded altimetric products? J. Geophys. Res. Oceans 2018, 123, 7220-7236. [CrossRef]

15. Fu, L.-L.; Cherchali, S.; Vaze, P. Surface Water and Ocean Topography Mission (SWOT) Project-Science Requirements Document; JPL D-61923; NASA: Washington, DC, USA, 2015.

16. Peral, E.; Esteban-Fernandez, D. SWOT mission performance and error budget. In Proceedings of the IGARSS 2018-2018 IEEE International Geoscience and Remote Sensing Symposium, Valencia, Spain, 22-27 July 2018; pp. 8625-8628.

17. Morrow, R.; Fu, L.-L.; Ardhuin, F.; Benkiran, M.; Chapron, B.; Cosme, E.; d'Ovidio, F.; Farrar, J.T.; Gille, S.T.; Lapeyre, G.; et al. Global observations of fine-scale ocean surface topography with the Surface Water and Ocean Topography (SWOT) mission. Front. Mar. Sci. 2019, 6, UNSP 232. [CrossRef] 
18. Fu, L.-L.; Ubelmann, C. On the transition from profile altimeter to swath altimeter for observing global ocean surface topography. J. Atmos. Ocean. Technol. 2014, 31, 560-568. [CrossRef]

19. Ubelmann, C.; Fu, L.-L.; Brown, S.; Peral, E.; Esteban-Fernandez, D. The effect of atmospheric water vapor content on the performance of future wide-swath ocean altimetry measurement. J. Atmos. Ocean. Technol. 2014, 31, 1446-1454. [CrossRef]

20. Ma, Z.; Han, G. Reconstruction of the surface inshore Labrador Current from SWOT sea surface height measurements. Remote Sens. 2019, 11, 1264. [CrossRef]

21. Hybrid Coordinate Ocean Model (HYCOM) Data. Available online: ftp://ftp.hycom.org/datasets/GLBu0.08/ expt_91.1/hindcasts/2015/ (accessed on 2 January 2020).

22. Kelly, K.A.; Thompson, L.; Cheng, W.; Metzger, E.J. Evaluation of HYCOM in the Kuroshio Extension region using new metrics. J. Geophys. Res. Oceans 2007, 112, C01004. [CrossRef]

23. Luecke, C.A.; Arbic, B.K.; Bassette, S.L.; Richman, J.G.; Shriver, J.F.; Alford, M.H.; Smedstad, O.M.; Timko, P.G.; Trossman, D.S.; Wallcraft, A.J. The global mesoscale eddy available potential energy field in models and observations. J. Geophys. Res. Oceans 2017, 122, 9126-9143. [CrossRef]

24. Nagano, A.; Ichikawa, K.; Ichikawa, H.; Konda, M.; Murakami, K. Volume transports proceeding to the Kuroshio Extension region and recirculating in the Shikoku Basin. J. Oceanogr. 2013, 69, 285-293. [CrossRef]

25. Dong, D.; Brandt, P.; Chang, P.; Schütte, F.; Yang, X.; Yan, J.; Zeng, J. Mesoscale eddies in the Northwestern Pacific Ocean: Three-dimensional eddy structures and heat/salt transports. J. Geophys. Res. Oceans 2017, 122, 9795-9813. [CrossRef]

26. Shchepetkin, A.F.; McWilliams, J.C. The regional oceanic modeling system (ROMS): A split-explicit, free-surface, topography-following-coordinate oceanic model. Ocean Model. 2005, 9, 347-404. [CrossRef]

27. Regional Ocean Modeling System (ROMS) Model Data off the Oregon Coast. Available online: https: //swot.jpl.nasa.gov/files/SWOTsimulator/swotsimulator_largedata.zip (accessed on 10 March 2020).

28. Bretherton, F.P.; Davis, R.E.; Fandry, C.B. A technique for objective analysis and design of oceanographic experiments applied to MODE-73. Deep Sea Res. Oceanogr. Abstr. 1976, 23, 559-582. [CrossRef]

29. Le Traon, P.Y.; Nadal, F.; Ducet, N. An improved mapping method of multisatellite altimeter data. J. Atmos. Ocean. Technol. 1998, 15, 522-534. [CrossRef]

30. Mason, E.; Pascual, A.; McWilliams, J.C. A new sea surface height-based code for oceanic mesoscale eddy tracking. J. Atmos. Ocean. Technol. 2014, 31, 1181-1188. [CrossRef]

31. Zeng, L.X.; Levy, G. Space and time aliasing structure in monthly mean polar-orbiting satellite data. J. Geophys. Res. Atmos. 1995, 100, 5133-5142. [CrossRef]

32. Itoh, S.; Yasuda, I. Characteristics of mesoscale eddies in the Kuroshio-Oyashio Extension region detected from the distribution of the sea surface height anomaly. J. Phys. Oceanogr. 2010, 40, 1018-1034. [CrossRef]

33. Sun, W.; Dong, C.; Tan, W.; He, Y. Statistical characteristics of cyclonic warm-core eddies and anticyclonic cold-core eddies in the North Pacific based on remote sensing data. Remote Sens. 2019, 11, 208. [CrossRef]

34. Sasaki, Y.N.; Minobe, S. Climatological mean features and interannual to decadal variability of ring formations in the Kuroshio Extension region. J. Oceanogr. 2015, 71, 499-509. [CrossRef]

35. Chen, G.; Tang, T.J.; Zhao, C.; Wu, S.; Yu, F.; Ma, C.; Xu, Y.; Chen, W.; Zhang, Y.; Liu, J.; et al. Concept design of the "Guanlan" science mission: China's novel contribution to space oceanography. Front. Mar. Sci. 2019, 6, UNSP 194. [CrossRef]

36. Qiu, B.; Chen, S.; Klein, P.; Wang, J.; Torres, H.; Fu, L.-L. Seasonality in transition scale from balanced to unbalanced motions in the world ocean. J. Phys. Oceanogr. 2018, 48, 591-605. [CrossRef]

37. Bai, Y.; Wang, Y.; Zhang, Y.; Zhao, C.; Chen, G. Impact of ocean waves on Guanlan's IRA measurement error. Remote Sens. 2020, 12, 1534. [CrossRef]

38. Ubelmann, C.; Cornuelle, B.; Fu, L.-L. Dynamic mapping of along-track ocean altimetry: Method and performance from observing system simulation experiments. J. Atmos. Ocean. Technol. 2016, 33, 1691-1699. [CrossRef]

39. Ruggiero, G.A.; Ourmières, Y.; Cosme, E.; Blum, J.; Auroux, D.; Verron, J. Data assimilation experiments using diffusive back-and-forth nudging for the NEMO ocean model. Nonlinear Proc. Geophys. 2015, 22, 233-248. [CrossRef]

(C) 2020 by the authors. Licensee MDPI, Basel, Switzerland. This article is an open access article distributed under the terms and conditions of the Creative Commons Attribution (CC BY) license (http://creativecommons.org/licenses/by/4.0/). 